\title{
The Challenges of Implementing Distance Education in Uganda: A Case Study
}

\section{Gudula Naiga Basaza}

Uganda Martyrs University, Uganda

\section{Natalie B. Milman}

The George Washington University, USA

\author{
Clayton R. Wright \\ Canada
}

\begin{abstract}
This brief case study provides a pithy introduction to Uganda and outlines key factors that affect the implementation of distance education in the nation: poor infrastructure, the high cost of an education, an outdated curriculum, inadequate expertise in distance education, and poor attitudes towards distance learning. These factors are also evident in other African countries.
\end{abstract}

Keywords: Distance education; Uganda

\begin{abstract}
About Uganda
The Republic of Uganda is a developing East African country with a population of 31 million people, 85\% of whom live in rural areas (World Bank, 2009). It possesses the following characteristics, as reported by the World Bank and UNICEF in 2009:

- a youthful population with children below 15 constituting more than half of the population;

- a ranking of 157 out of 182 countries on the human development index;

- a ranking of 91 out of 135 countries on the human poverty index;

- a high mortality rate due to poor sanitary conditions and a lack of funding to improve health services;

- a rate of $38 \%$ of the population living below the national poverty line; and

- an adult literacy rate of $74 \%$ (86\% for urban areas and $66 \%$ for rural areas).
\end{abstract}


Demographic surveys conducted by the Uganda Health Services reveal that increasing education levels in Uganda are proportional to improvements in key health indicators (Uganda Demographic and Health Services survey, 2006). Thus, the provision of accessible and quality education is essential for the health of the people. In addition, education is important for the economic growth of the country.

The government of Uganda gives priority to education as evidenced by increased budget allocations and by the introduction of free primary education in 1997. Primary level enrolment has increased from 2.6 million in 1995 to 7.4 million in 2008 (Uganda Bureau of Statistics, 2009). Universal secondary education was introduced in order to absorb the increasing number of students who completed primary education. Now, institutions of higher learning are unable to accept all of the secondary school graduates who qualify and who want to enroll. Between 9,000 and 12,000 students qualify for postsecondary education, but only $25 \%$ of them are accepted into college or university (Experience Africa, 2009). The enrolments in tertiary institutions have increased $90 \%$ during the last 10 years, but the number of tertiary institutions has increased by only 1.8\% during the same period (MyUganda, 2010).

In order to meet the needs of those seeking postsecondary education, but who are denied entry, and in order to improve the health of the citizens and the economy of the country, Uganda must provide additional access to higher education. Distance education (DE) could provide this access.

\section{The Challenges}

Higher education could accelerate development within Uganda. However, there are several major challenges that must be addressed. Each is outlined below.

\section{Infrastructure for Higher Education}

Uganda currently lacks the physical and human infrastructure to cope with the demand for postsecondary education. Further, accessibility to postsecondary education is affected by the distribution of institutions throughout the country. Most of the 31 registered universities are located in the central or urban region of the country, yet the majority of the population lives in rural areas. The distribution of institutions affects the cost of access. Most of the students are not able to commute from their homes to institutions located in urban areas; thus, they must live near the institution and thereby incur additional costs.

The surface area of Uganda is small, allowing people to move from one border to another in a day - a very long day over sub-standard roads. The sole means of transport is by road, using buses and minibuses as few Ugandans own vehicles. The roads, even those with asphalt, are in poor condition and are not lighted. Due to poor road conditions, the poor mechanical conditions of the vehicles, and speeding, at least 2,000 people die annually from road accidents and about 10,000 are injured (Naturinda, Bagala, \& Mugaga, 2009). Thus, transportation is a limiting factor to educational access. Distance education addresses this barrier. 
The building of educational facilities has not kept pace with postsecondary student enrolment, which grew from 5,000 in the 1970s to 124,314 in 2005 (Kasozi, 2006). Consequently, most postsecondary institutions have enrolments that exceed the available space in lecture halls and in libraries. Students are often seen sitting outside the lecture room as classes are conducted. In addition, the current number of students overwhelms available resources, such as books, Internet access, and study space. Digital resources, which a number of universities subscribe to, are available, but due to low Internet bandwidth, impatient students give up before they can access the material they want. In some institutions, the ratio of students to computers is so high that the scramble to access a computer becomes an obstacle to peaceful learning and research. Distance education, may, in part, address the enrolment and space pressures occurring at face-to-face institutions, but distance students will also need access to technological resources.

The National Council of Higher Education in Uganda sets standards for teaching and learning in postsecondary institutions. The Council recommends the number of doctoral and master's degree holders that should be employed by each institution. These percentages are not met, especially by new and rural universities. The number of qualified lecturers is limited by the lack of affordable opportunities for further study within Uganda. Thus, if they can afford it and/or if they receive bursaries, students are likely to obtain further education outside of the country. Due to poor pay, about US\$400 per month, lecturers teach in a number of institutions to make ends meet. This situation compromises the time allocated to (and thus the quality) of teaching and student support because lecturers are constantly moving from one institution to another. Distance learning that utilizes technology should minimize the movement of lecturers between institutions that share instructors. But the widespread implementation of educational technology cannot occur until challenges with the electrical and telecommunications infrastructure are addressed.

Globally, distance learning makes use of information and communication technologies (ICTs) to deliver learning opportunities as well as to provide access to resources and to facilitate interactivity. However, distance learning in Uganda is dependent on printed modules with supplementation by face-to-face sessions (Basaza, 2006). If technology is used to deliver or to enhance distance learning, a reliable electrical grid must be accessible. Unfortunately, electricity is not always available 24 hours per day, 7 days per week in Uganda. As Uganda is a land-locked country, obtaining diesel fuel for electric generators can be expensive. Further, connectivity to the electrical grid declined O.4\% in 2008 (Uganda Bureau of Statistics, 2009), while elsewhere in Africa connectivity increased.

\section{The Cost of Higher Education}

The comparatively high cost of postsecondary education is a barrier to those who want to enroll. On average, a postsecondary student in Uganda requires US\$2,000 per year for tuition and upkeep. Access to tuition loan systems is minimal; thus, potential students and their parents have limited access to extra funds. Even the government institutions admit students predominately on private sponsorship. Tuition fees, books, educational supplies, and living expenses must be paid by parents and students. Note, however, that only about $5 \%$ of the working population has permanent paid employment (Uganda Bureau of Statistics, 2009). The median monthly wage is 
US\$18 (US\$24 for male and US\$10 for female employees) (Uganda Bureau of Statistics, 2009). Consequently, it is easier for Ugandan families to save US\$500 for one year of distance education than to save US\$2,000 for one year of traditional, on-campus instruction.

\section{The Relevance of the Curriculum}

The education system in Uganda is being challenged to produce job creators rather than job seekers. The curriculum has not been adapted to suit contemporary needs (Kasozi, 2006). Current teaching promotes rote learning rather than application, problem-solving, and entrepreneurial skills. Kagoda (2009) decried the process of curriculum reform: "We need the input of the private sector, Federation of Uganda Employers, parents, experienced educationists, retired teachers and any other stakeholders. If half-baked graduates affect us all, then why can't we be consulted on something as important as curriculum?” Rubanju (2008) recommends a fundamental restructuring of the ways in which teaching and learning are delivered, including regular curriculum reviews and the use of ICTs. Rubanju notes that in the traditional lecture hall or classroom, theory and applications are not linked. Studying via distance learning will allow students to apply theories to their own settings and to observe the effect on their environment. The results of these activities could inform curriculum reform and spur the introduction of educational theories and practices that are suitable for the current context in Uganda.

\section{Inadequate Expertise in Distance Education}

Most of the university lecturers do not have a background in education or in instructional and learning methodology. Instead, they have degrees in various subjects and are hired by universities on that basis. Some have obtained guidance about how to teach in a face-to-face setting from colleagues, but very few have experience with distance education instruction and learning strategies. Their inadequacy is reflected in the lack of quality instruction, the lack of quality distance learning materials, and the lack of student support. Students are frustrated with this lack of support, but they are also challenged by the mode of delivery - print! The Ugandan culture tends to be a verbal, or talking, culture; thus, students feel pressure when they are expected to read and write for extended periods of time.

\section{Poor Attitudes towards Distance Learning}

The majority of distance learners in Uganda are employed or involved in subsistence farming and fishing. They enroll in distance education in order to obtain a qualification and/or a promotion. They want to update their knowledge and skills. Some enroll in distance education courses with the attitude that distance education is easy because they can learn at their own pace; however, distance learning requires self-discipline and self-management. Unfortunately, some students drop out or do not graduate. Also, some lecturers believe that once you choose to study at a distance, you do not need extra support. Sensitization and exposure to distance education methods will help students and lecturers to alter their attitudes towards distance education in a land that prizes face-to-face interactions and on-campus instruction. 


\section{Interventions for Enhancing Distance Education in Uganda}

In order to address the lack of resources in the educational system, institutions must collaborate among themselves and with business to provide an infrastructure that will support distance learning. Institutions that offer distance learning are making minimal efforts to establish resource centres in various regions of the country due to prohibitive costs. However, if institutions combine their resources, they could establish state-of-the-art resource centres for use by all of their students.

Distance learning offers business opportunities for investors. For example, distance institutions could reach a memorandum of understanding with an investor to establish a modern resource centre, and payment could be made over time. The business school at Makerere University, Uganda's oldest and largest university, used this approach to establish a computer laboratory. Students were levied a small annual fee to cover the construction and equipment costs of the centre.

When an institution offers education, it does so on behalf of the state, regardless of whether it is sponsored privately or by the government. Thus, within its mandate, the government should prioritize educational infrastructure, including the construction of educational buildings. Priority should be given to establishing a reliable electrical grid, increasing access to the grid, providing Internet broadband connectivity, and facilitating the import of telecommunications equipment, such as computers. The government is not a limitless resource and cannot fully subsidize the education and ICT sectors, but these sectors are drivers of human and economic development.

The poor attitudes students may have towards distance education could be addressed through sensitization, orientation, and the provision of tool kits that help users to study at a distance. Prospective students must be informed that distance education is not easy; rather, it requires selfdiscipline. The public-at-large could be informed about the benefits of distance education: It is not only cost-effective but also enables people to study where they live and to contribute to their families and communities as they study.

Lecturers must receive training in on-campus and distance instructional methods and learning strategies. These sessions can be offered at their current institutions as a job requirement. Teaching will not be recognized as a profession until it is treated as such and individuals who lecture are required to obtain training and to receive some form of certification.

When the quality of distance education is improved as a result of updated curricula, improved instructor training, the provision of modern resource centres, and access to broadband Internet services and reliable power, the attitudes towards distance education will change. At the same time, it must be recognized that distance education is compared to traditional face-to-face instruction in Uganda; however, it is unclear whether the tendency to use rote learning on-campus is a better alternative to instruction delivered via a distance format. 


\section{Conclusion}

Uganda, like many other developing countries, is benefiting, and will continue to benefit from, the implementation of distance education. DE provides flexibility for students, reduces the need for educational buildings, reduces transportation costs incurred by students, allows students to remain with their families and communities, and enables tuition fees to be set relatively low when compared to on-campus tuition fees. In Uganda, however, the success of distance education is inhibited by poor infrastructure, the relatively high cost of an education, an irrelevant curriculum, inadequate expertise in distance education, and poor attitudes towards distance learning. Globally, the use of educational technologies is increasing because the technologies can help bridge the distance between the learners and their learning environment. The increased use of educational technology in Uganda will only exacerbate existing challenges, which must be addressed. Distance learning is unlikely to succeed without collaboration involving the government, the educational institutions, and the business community. 


\section{References}

Basaza, N. G. (2006). Distance education and realistic teacher education pedagogy in Uganda: Impact of an ICT-based learning environment (Unpublished doctoral thesis). University of Ghent, Belgium.

Experience Africa (2009). Information about primary and secondary schools in Uganda. Retrieved from http://www.experienceafrica.co.uk/J1.htm.

Kagoda, M. (2009). Consult widely before curriculum review. Retrieved from http://www.newvision.co.ug/D/9/35/697700.

Kasozi, A. B. K. (2006). A proposed quality assurance framework for institutions of higher learning in Uganda. Paper presented at the seminar on Quality Assurance in Tertiary Education, Servres, France.

MyUganda (2010). Education in Uganda. Retrieved from http://www.myuganda.co.ug/edu/.

Naturinda, S., Bagala, A., \& Mugaga, H. (2009). Road accident claims life of Budiope legislator. Retrieved from http://allafrica.com/stories/200912010546.html.

Rubanju, A. C. G. (2008). Quality challenges in higher education institutions in Uganda. M.Phil Higher Education (HE), Faculty of Education, Institute for Educational Research. University of Oslo. Retrieved from http://www.uv.uio.no/studentliv/isne/assets/docs/Unit\%201\%20paper\%20assignment.doc

Uganda Bureau of Statistics (2009). Statistical abstract. Retrieved from http://www.ubos.org/onlinefiles/uploads/ubos/pdf\%20documents/2009Statistical_\%20Ab stract.pdf.

Uganda Bureau of Statistics (2006). Uganda demographic and health survey. Retrieved from http://www.measuredhs.com/pubs/pdf/FR194/FR194.pdf.

UNICEF (2009). Uganda statistics. Retrieved from http://www.unicef.org/infobycountry/uganda_statistics.html.

World Bank (2009). Uganda. Retrieved from http://ddpext.worldbank.org/ext/ddpreports/ViewSharedReport?\&CF=\&REPORT_ID=91 47\&REQUEST_TYPE=VIEWADVANCED.

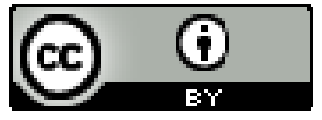

